\title{
ARTE E CIDADE COMPRIMIDAS: A EXPOSIÇÃO COMO SÍMBOLO DA MODERNIDADE EM GEORG SIMMEL
}

\author{
Compressed art and city: the exhibition as a modernity symbol in Georg Simmel
}

\author{
Tálisson Melo de Souza'
}

\begin{abstract}
Resumo
Neste artigo, proponho uma leitura de dois ensaios escritos pelo filósofo e sociólogo Georg Simmel sobre diferentes tipos de exposições, a de obras de arte e a de produtos industriais - a saber, Über Kunstausstellungen (Sobre Exposições de Arte), de 1890, e Berliner Gewerbe-Ausstellung (Exposição Industrial de Berlim), de 1896, respectivamente. Busco compreendê-los em relação com o escopo mais amplo da formulação teórica de Simmel sobre o estilo de vida moderno. Destaco na abordagem simmeliana do significado da exposição para a modernidade sua compreensão do fenômeno como forma de associação desenvolvida no interior de uma rede de interações infinitas. Sua visão fornece caminhos para análise das afetações mútuas entre vida mental e sensibilidade estética dos indivíduos, temporalidade, modos de participação na produção e recepção das realizações da cultura, e da realidade social. Também trago, para comparação, atualização e abertura de questões contribuições de outros autores sobre as exposições, essas advindas da psicologia, estética e sociologia da arte.
\end{abstract}

Palavras-chave: Georg Simmel; exposições de arte; exposição industrial; modernidade; metrópole.

\begin{abstract}
In this article, I propose an analysis of two essays written by the philosopher and sociologist Georg Simmel about different types of exhibitions: art works and industrial products exhibitions - one published in 1890 Über Kunstausstellungen (On Art Exhibitions), and the other, Berliner Gewerbe Ausstellung (Berlin Trade Exhibition), from 1896. I read them in relation to the broader scope of Simmel's theoretical formulation on the modern lifestyle. In the simmelian approach of the meaning of the exhibition for modernity, what I emphasize is his understanding of the phenomenon as a form of association developed within a network of infinite interactions. This view provides ways to analyze the mutual affections between mental life and aesthetic sensibility of individuals, temporality, modes of participation in the production and reception of cultural achievements, and social reality. I also bring, for comparison, updating and opening of questions, contributions by other authors on the exhibitions, those coming from the psychology, aesthetics and sociology of art.
\end{abstract}

Keyword: Georg Simmel; art exhibition; industrial exhibition; modernity; metropolis.

\footnotetext{
1 Programa de Pós-Graduação em Sociologia e Antropologia do Instituto de Filosofia e Ciências Sociais da Universidade Federal do Rio de Janeiro (PPGSA/IFCS/UFRJ). Email: talissonmelo@yahoo.com.br
} 


\section{Introdução}

Em 1918 - data de publicação dos últimos escritos de Georg Simmel (Berlim, 1858-1918) e de seu falecimento em Estrasburgo, França -, o filósofo e matemático Benjamin Ives Gilman (Nova York, 1852-1933), então secretário do Boston Museum of Fine Arts, publicava, nos Estados Unidos, seu livro Museum Ideals of Purpose and Method, um amplo estudo sobre as estratégias de efetivação dos objetivos dos museus sobre seu público. Na secção do livro dedicada aos métodos de colecionismo, construção, instalação, divulgação e administração dessas instituições e das exposições que promove, consta um capítulo dedicado a uma análise empírica que buscava determinar os tipos e quantidade de 'esforço muscular' que a experiência de visitar exposições em museus exigia do visitante, a partir do qual o autor se propunha compreender o surgimento do que chama "museum fatigue"2, tratado como um sintoma da experiência proporcionada pelo padrão mais adotado de instalação das exposições, e que deveria ser solucionado.

A minúcia com que são analisados os depoimentos e inúmeras fotografias de um visitante ideal - "an inteligent man with good eye-sight and well accostumed to museums and its contents" (GILMAN, 1918, p. 251) -, buscava dar conta de todas as posições e os movimentos que um individuo deveria fazer para apreciar as peças expostas nos diferentes dispositivos de apresentação (pendurados nas paredes, dentro de vitrinas e caixas verticais, horizontais, diagonais, em pedestais de alto e baixo nivel, podendo mostrar diferentes quantidades de objetos simultaneamente).

Embora Gilman tenha residido na Alemanha em meados da década de 1880, não consta nenhuma referência direta aos textos de Simmel em seu trabalho. Nem mesmo pude identificar em sua perspectiva alguma influência da abordagem simmeliana integrada a uma concepção teórica mais ampla sobre a modernidade, suas observações sobre museus, exposições de arte ou de objetos industriais, suportes de apresentação de obras como a moldura, a arquitetura e a iluminação das peças, nem a própria visão e a percepção do

\footnotetext{
2 O subitem intitulado Museum Fatigue foi publicado anteriormente, em janeiro de 1916, na revista The Scientific Monthly.
} 
público que aflui nesses espaços - como nos dois textos enfocados neste artigo: Über Kunstausstellungen (Sobre Exposições de Arte), de 1890², e Berliner Gewerbe-Ausstellung (Exposição Industrial de Berlim), de $1896^{4} .^{5}$

A fadiga identificada na experiência de visitações a museus, na visão de Gilman, parece perder de vista a experiência mais complexa e expandida dos indivíduos em grandes cidades, com seu ritmo, velocidade, movimentação e oscilação de estímulos apontados por Simmel com especial insistência no decorrer de sua obra. Trago a contribuição de Gilman à abertura deste artigo para evidenciar, do contraste das duas abordagens, um aspecto fundamental da observação de Simmel: o movimento complexo que se desenha da relação entre um fluxo da vida, a vivência cotidiana nas metrópoles que crescem rápida e intensamente na virada para o século XX, e determinadas formas fixas erigidas, como na experiência específica de percorrer o interior das exposições.

A atenção direcionada por Simmel à dimensão estética das experiências e condutas que se configuravam no espaço urbano é formulada numa abordagem que compreende a cidade como objeto artístico. Em um de seus ensaios mais conhecidos no Brasil, As grandes cidades e a vida do espirito, de 1903, Simmel identifica dois efeitos a partir da intensificação dos estímulos à percepção do indivíduo na metrópole: nos trajetos realizados diariamente entre avenidas, ruas, fábricas, lojas, trens e uma multidão crescente de pessoas, se observam as atitudes de reserva e indiferença, num sentido de normalização do excesso de estímulos, por outro lado, uma busca incessante por divertimento e contato com novas atividades e informações também emerge. Ambos traços parecem compor um movimento oscilatório de busca entre estados de anestesia e hiperestesia, que tratarei com mais detalhes adiante.

\footnotetext{
3 Publicado na revista alemã Unsere Zeit, segundo volume, número 11, de 26 de fevereiro de 1890. Assinado apenas como "S.".

${ }^{4}$ Publicado na revista austriaca Die Zeit, número 95, de 25 de julho de 1896.

5 Há duas traduções de Über Kunstausstellungen para o português: a realizada por Laura Rivas Gagliardi (em Georg Simmel: O Conflito da Cultura Moderna e outros escritos. Organizado por Arthur Bueno, Editora Senac, 2013), e a segunda por Markus André Hediger (em Georg Simmel, arte e vida: ensaios de estética sociológica, organizado por Glaucia Villas Bôas e Berthold Oelze, Hucitec Editora, 2016). Ambas foram consideradas, e não apresentam divergências acentuadas de sentido. Para as citações optei pela versão de 2016, por ter tido contato com ela antes da mais antiga. A única tradução de Berliner Gewerbe-Ausstellung ao português encontrada é feita por Laura Rivas Gagliardi (em BUENO, 2013).
} 
Os textos de Simmel enfocados neste artigo referem-se ao mesmo tempo a exposições concretas e a um desenvolvimento histórico das formas de expor objetos. A escrita desses textos situa-se na última década do século XIX, quando a tradição de quatro décadas de exposições de grande escala (as Feiras e Exposições internacionais, "mundiais" ou "universais"6, em que objetos e materiais de várias nações, desde a produção de matérias-primas, manufaturas, inovações industriais, até a pintura e a escultura ${ }^{7}$ ), realizadas entre cidades da Europa Ocidental e dos Estados Unidos ${ }^{8}$, desdobravam-se em maior volume, frequência, especialidade e cobertura geográfica, com diferentes tipos de eventos que emergiam dessas formações.

Ao abordar estes ensaios, busco identificar a maneira como Simmel integra as exposições e a experiência de sua visitação às cidades em que estas ocorrem e à experiência de viver nelas, sujeito à intensificação de seus estímulos. Tento situar o papel atribuído pelo autor às exposições no interior da sua formulação mais detalhada acerca da modernidade. Para isso, tomo como base a elaboração de seu conceito de "estilo de vida", em seu livro Philosophie des Geldes (Filosofia do Dinheiro), de 1900, bem como outros ensaios posteriores que evidenciam essas relações.

\section{Pensando dentro da cidade grande: cristalizações em fluxo}

No desdobramento de sua produção de ensaios ${ }^{9}$, Georg Simmel apresentou análises sobre o presente que evidenciam a elaboração de uma

\footnotetext{
6 Ver: PESAVENTO, 1997.

7 A crítica de Charles Baudelaire (Paris, 1821-1867) à versão de 1885 da Exposition Universelle de Paris, permite identificar o entusiasmo na recepção desse tipo de mostras: "Il est peu d'occupations aussi intéressantes, aussi attachantes, aussi pleines de surprises et de révélations pour un critique, pour un rêveur dont l'esprit est tourné à la généralisation aussi bien qu'à l'étude des détails, et, pour mieux dire encore, à l'idée d'ordre et de hiérarchie universelle, que la comparaison des nations et de leurs produits respectifs. [...] que ferait, que dirait un Winckelmann moderne (nous en sommes pleins, la nation en regorge, les paresseux en raffolent), que dirait-il en face d'un produit chinois, produit étrange, bizarre, contourné dans sa forme, intense par sa couleur, et quelquefois délicat jusqu'à l'évanouissement ?' (BAUDELAIRE, 1868, p. 212-213).

8 No decorrer do século XIX, seguindo a Grande Exposição de Londres considerada pioneira (oficialmente chamada de Great Exhibition of the Works of Industry of all Nations), realizada em 1851, tiveram destaque as mostras congêneres organizadas em Paris, 1855; novamente em Londres, 1862; Porto, 1885; pela segunda vez em Paris, 1867; Viena, 1873; Filadélfia, 1876; terceira vez em Paris, 1878; Sydney, 1879); Melbourne, 1880; Nova Orleans, 1884; Barcelona, 1888; por quarta vez em paris, 1889; Chicago, 1893; e Bruxelas, 1897.

9 Conforme apresentado pelo pesquisador Leopoldo Waizbort em As Aventuras de Georg Simmel, o ensaio é a forma literária mais conectada com o presente de Simmel e é a possibilidade de formulação de sua "cultura filosófica". Ver: Waizbort, 2000. Ver também: Frisby [1990], 2004.
} 
concepção da realidade que aproximava-se progressivamente do vitalismo ${ }^{10}$ em voga na Alemanha na virada para o século XX e primeiras décadas deste século. Considerando cada unidade a que se dedicou observar (desde uma ponte e uma moldura de quadro até o dinheiro, o conflito e o amor, passando pelas metrópoles e as exposições que nelas se apresentavam), como formas que se cristalizam e fluidificam pelo fluxo efervescente de pulsões vitais - compondo uma "rede infinita de relações recíprocas entre uma infinidade de elementos" (CAVALLI, apud. VANDENBERGHE, 2005, p.72).

Simmel transmite em suas ideias a percepção de um caráter trágico e transitório da vida. Essa maneira de compreender a realidade e objetivá-la na forma de produção de conhecimento pressupõe a infinitude ontológica da realidade mesma, abordagem que constitui o escopo de sua sociologia vitalista. No conjunto de sua obra, o filósofo-sociólogo propõe uma perspectiva dialética para exploração do processo gerador e conflituoso que envolve formas e vida. Tratando o contexto em que vive particularmente, o autor identifica a emergência da tragédia da cultura (moderna) ${ }^{11}$, cujas raízes se encontram no conflito essencial entre vida e formas, esse movimento dualista ${ }^{12}$ permeia toda sua análise de objetos delimitados.

Esse conflito é a conjugação de uma infinidade de tensões entre formas de fixidez (as cristalizações) derivadas de um movimento constante (o fluxo da vida), que se compõem e recompõem a partir da dinâmica das relações entre todos os elementos. Cada ensaio apresenta-se como peça particular de um escopo teórico muito mais amplo que se projeta da recursividade explicita entre eles.

Atentando para essas indicações, o conjunto de sua obra permite observar o movimento de pensamento que Simmel percorreu, na medida em que a perspectiva adotada predominantemente oscila de uma visão do detalhe (como da asa de um jarro ou dos traços do rosto), passando por um enquadramento mais ampliado (quando pensa a moda, as exposições, a

10 Ver: Vandenberghe, 2005, especialmente o sexto capítulo, Filosofia da vida e da cultura (pp.163195).

11 Ver: Simmel [1917], 2016; Simmel [1917], 2013; Simmel [1918], 2013; Simmel [1918], 2011.

12 Ver: Vandenberghe, 2005, particularmente o segundo capítulo, Um pensamento, o dualismo (pp. 55$76)$. 
prostituição, as sociedades secretas, e a alimentação, entre outros fenômenos tratados), até englobar de modo mais abrangente o amor, a história e toda sociedade monetária.

Através de uma reflexão profunda sobre o dinheiro, considerado como um meio de relações de troca que, ao se transformar em um fim em si mesmo, passava a assumir o papel mais comum entre todos os elementos característicos da modernidade (do seu tempo presente, da era moderna, Neuzeit), um mediador, par excellence, onipresente - Simmel traça a forma das interações nesse tempo, comparando-a com as de outras unidades da história e da psicologia de diferentes povos, e indicando o processo de racionalização que passa a ser preponderante nas relações modernas, configurando um estilo de vida característico, singular a essa sociedade como um todo. O dinheiro é inclusive visto, em analogia, como o Deus dessa época, por sua dupla função que, ao mesmo tempo em que, por um lado, separa os indivíduos e os objetos nas relações de produção e consumo, por outro, os une devido a sua "falta de caráter"13.

O pensamento de Simmel, pela dinâmica e forma que apresenta, pode ser visto em relação com o contexto material e existencial em que se insere. Simmel nasceu em Berlim, em 1858, e viveu a maior parte de sua carreira nessa cidade, até seu falecimento, em 191814. Nessa cidade, pôde experimentar e refletir sobre as transformações que se adensavam a partir dos anos das guerras dos anos de $1870^{15}$ e sob o Segundo Império na Alemanha, marcando uma virada de projeção mundial da nação como uma potência (como cidade mundial, Weltstadt, como propõe Simmel).

O adensamento populacional dos centros urbanos industrializados em intenso crescimento progressivo, acelerando-se em poucas décadas, esteve relacionado com a intensificação do comércio e do trabalho assalariado, de modo que o dinheiro se estabelecia como esse mediador comum do mais alto ao mais baixo nivel das classes econômicas e profissionais. As cidades grandes, concentrando em si as características e as contradições do

\footnotetext{
13 Ver: Simmel [1900], 2004. Especialmente o capitulo intitulado The Style of Life (pp. 433-518).

14 Waizbort apresenta uma análise detalhada da relação de Simmel com o contexto da Berlim no Segundo Império e com seus "círculos sociais", considera as exposições entre outros espaços. Ver: Waizbort, 2000.

15 Ver: Simmel, 1902.
} 
desenvolvimento da sociedade monetária (mobilidade, individualidade, velocidade e diversidade de estímulos), são experimentadas e observadas como lugar privilegiado para a análise da cultura moderna em diferentes perspectivas e com foco em diferentes fenômenos e suas relações.

O pensamento de Simmel está conectado, em sua forma e seu conteúdo, com a experiência e a preocupação de um indivíduo que se move por diferentes círculos sociais, e, nesses trajetos de interação, se compõe e se individualiza, como elemento de uma dinâmica que, de acordo com o próprio autor, só é possível no espaço da metrópole. Entre salões, exposições e suas aulas, Simmel compôs uma reflexão complexa que evidencia a ambiguidade dos fenômenos que buscava descrever a partir de uma rede de relações - o que se dá até mesmo entre os seus ensaios.

Na obra de Simmel, um exemplar especial dessa recursividade, entre textos e a experiência no contexto metropolitano, é a cocnferência Die Großstädte und das Geistesleben (As Grandes Cidades e a Vida do Espírito) uma versão atualizada e resumida de algumas questões anteriormente detalhadas por Simmel em Filosofia do Dinheiro -, proferida na ocasião de uma exposição municipal realizada na cidade de Dresden, em 1903, a primeira Deutsche Städte-Ausstellung (Exposição das Cidades Alemãs).

Nesse texto, Simmel parte da proposta de uma historicização do problema da equalização entre conteúdos individuais e supra-individuais (coletivos), para pensar sobre o fundamento psicológico em que se fundamenta o tipo de individualidade específico que surge no contexto das cidades grandes, o que ele chama de "intensificação da vida nervosa" (SIMMEL [1903] 2005, p. 577).

O elemento reiterado ao longo desse texto é a noção de "estímulo", direcionada a refletir sobre a incrementação da produção e disponibilidade desses no espaço das grandes cidades, afetando os indivíduos ao longo de seu deslocamento e no âmbito de sua sociabilidade. Esses estímulos, na concepção de Simmel, geram duas reações em sentidos opostos, mas que também se complementam para promover determinados objetos e eventos de associação e dissociação. 
A primeira reação, que se define pelo caráter blasé dos estados de alma dos indivíduos nas grandes cidades, diz respeito à intensificação da intelectualidade e da necessidade de reserva e autopreservação pessoal diante do fluxo incessante de novos estímulos materiais e visuais presentes no ambiente metropolitano. Como escreve o autor, essa condição origina uma "incapacidade de reagir aos estimulos com uma energia que lhes seja adequada" (ibid., p.581). Em sentido oposto, ele identifica outro movimento que se dá simultaneamente ao aumento da indiferença (uma rejeição a se afetar e reagir) frente à diversidade e intensidade de estímulos presentes na cidade grande, e que também define a vida na metrópole: a necessidade e a busca infinda pela "diferenciação, o refinamento e o enriquecimento das necessidades do público" (ibid., p. 587), levando à criação de estímulos sempre novos e singularidades qualitativas.

Ambos movimentos reativos e criativos podem ser lidos em outros ensaios de Simmel, destacadamente em Die Mode (A moda), de 1911, porque nesse elabora de modo sintético o conflito entre a expressão da singularidade e o agir unitário (entre tendência à distinção individual e a uniformização social) que convergem na história da moda como sucessão de "tentativas de acomodar ao estado de cada cultura individual e social a satisfação dessas duas tendências opostas" (SIMMEL [1911], 2008, p. 165).

Outro exemplo de objeto emergente no século XIX em que convergem ambos movimentos é a constituição de grandes exposições temporárias de belas artes que reuniam estilos de diferentes regiões e períodos a disposição de um único passeio ${ }^{16}$, competindo com as galerias de exibição dos acervos permanentes dos museus, como as mostras internacionais abrigadas pelo Glaspalast de Munique em 1886 e 1888, a I Esposizione Internazionale d'Arte dela Città di Venezia, inaugurada em 1895, e a Annual International Carnegie Exhibition, em Pittsburg, lançada em 1896.

A fundação de instituições para administrar e promover essas exposições temporárias da produção artística de vários países em uma só cidade está diretamente relacionada ao desenvolvimento industrial de

\footnotetext{
16 A historiografia das exposições de arte vem buscando traçar os antecedentes dessas mostras, às vezes chegam a encontra-los nas medievais feiras, festas populares, carnavais, "ostentórios" de reliquias; outros partem da Wunderkammer ou gabinetes de curiosidades. Ver: BYDLER, 2004.
} 
cidades ao redor do mundo, que também se configuravam como espaços cosmopolitas, onde também iniciava-se ou consolidava-se um mercado de bens culturais ${ }^{17}$. Ao longo do século XX é possivel identificar a continuidade do processo de expansão de uma verdadeira rede de exposições temporárias de arte nos cinco continentes. Da mesma forma seguem sendo realizadas exposições da produção industrial ${ }^{18}$, nos mesmos moldes, convivendo com os museus de ciências naturais, ciências e tecnologia.

A análise de Simmel integra essas exposições ao espaço das grandes cidades de final do século XIX e fornece caminhos de análise bastante interessantes para se pensar esses eventos e instituições no decorrer de suas transformações ao longo do século XX, alcançando nossos dias. A abordagem sobre a dimensão sensorial que Simmel sustenta nesses ensaios, ao ser lida atualmente, evoca inclusive a emergência de um modelo expográfico que se estabeleceu por volta dos anos de 193019, como hegemônico - a galeria de paredes brancas e lisas, com obras espaçadas entre si, na altura média do olhar e com iluminação focalizada -, notável de maneira preponderante até nas exposições atuais. Embora tenham havido importantes propostas em direções diversas ${ }^{20}$, e um insistente questionamento desse padrão passa a ter cada vez mais espaço, visibilidade e legitimação,

O rótulo de "cubo branco" que esse modelo recebera do artista e crítico irlandês Bryan O’Doherty, através de uma série de ensaios publicada na revista Artforum, em 1976, com o titulo Inside the White Cube: Ideologies of the Gallery Space, expressava, segundo seu próprio proponente, um incômodo compartilhado entre várias pessoas sobre os efeitos da permanência dessa forma de expor, a despeito das transformações

\footnotetext{
17 A Bienal Internacional de São Paulo, inaugurada em 1951 por iniciativa do industrial italo-brasileiro Francisco Matarazzo Sobrinho (São Paulo, 1898-1977), é a primeira do gênero a se estabelecer fora do eixo Europa e Estados Unidos, conformando-se como a principal instituição de projeção da arte moderna e contemporânea da América Latina até meados da década de 1960, quando tem início uma espécie de boom de bienais internacionais em crescimento progressivo, alcançando os cinco continentes.

18 Estas também podem ter seus antecedentes remontados ao Renascimento com as Schtzkammer (salas do tesouro).

19 Difundido com destaque pela instalação da exposição "Cubism and Abstract Art", criado pelo crítico Alfred Hamilton Barr Jr. (1902-1981), então diretor do Museum of Modern Art de Nova York, em 1936. 20 Como as realizadas por Marcel Duchamp (1887-1968), Exposition Internationale du Surréalisme, na Galérie Beaux-Arts, Paris, em 1938, e First papers of Surrealism, na mansão Whitelaw Reid, em Nova York, 1942 - sempre relembradas pela historiografia recente da curadoria de exposições de arte.
} 
concernentes às obras de arte expostas. Nos ensaios de O'Doherty, no entanto, considerando o "cubo branco" expressão da ideologia modernista um espaço vazio, um "lugar onde as coisas acontecem" (O’DOHERTY, [1976] 2002, p. 36) -, identifico um movimento analítico distinto, que encontra nas próprias obras, "a superfície pictórica como uma unidade de discurso" (idem.), as bases de definição do espaço dentro do qual também percorre um fantasma, o espectador. Sobre esse elemento necessário para a existência da exposição O’Doherty lança uma das questões centrais de seu texto: “Quem é o Espectador, também chamado de Visitante, às vezes chamado de Observador, ocasionalmente de Percebedor?” (ibid., p. 37).

A leitura dos ensaios de Simmel sobre as exposições em suas articulações com o escopo mais amplo de sua obra filosófica e sociológica oferece caminhos para se pensar as relações entre os indivíduos que visitam os espaços expositivos, as especificidades formais e estruturais desses espaços e das experiências que neles se realizam, e a dinâmica cultural dos centros urbanos no fin de siècle. O olhar de Simmel sobre as exposições e sobre a experiência do olhar nas exposições situa o espectador e sua percepção no interior de uma infinita rede de relações que extrapola as paredes nas quais os quadros são pendurados, considerando diversos aspectos que compõem o estilo de vida moderno.

\section{A qualidade-vitrine das coisas em exposição}

No ensaio Berliner Gewerbe-Ausstellung (Exposição Industrial de Berlim), de 1896 - em que Simmel elabora uma reflexão sobre uma exposição que reunia no interior de um espaço projetado e construído para abrigar por oito semanas a produção mais variada do conjunto de indústrias estabelecido em Berlim, em sua variedade de formas, funções e modos de apresentação -, é possivel acompanhar a mostra pelos olhos de um visitante atento a detalhes do espaço circundante aos objetos, a cenografia, iluminação e disposição são elementos centrais para a análise que Simmel propõe.

Nesse ensaio, como nos dois acima mencionados, a divisão do trabalho é apontada como causa do desencadeamento da indiferença e 
individualização, efeito de uma especialização progressiva da atividade humana que leva, de modo ambíguo, à autonomia (dos objetos, dos meios e do trabalho, por exemplo) e à dependência (da perda do contato com a totalidade, se estabelecem várias dependências entre os seres humanos e as coisas). Essa contradição é formulada como um conflito, um movimento inerente ao processo de vir a ser sociedade (o processo de sociação Vergesellchaftung). O modo de trabalho que tende à especialização e, logo, à repetição de tarefas, levando o indivíduo a viver uma rotina monótona, dá-se no mesmo contexto em que se acende a consciência da coexistência de uma diversidade de conteúdos, os estímulos que se oferecem a todo indivíduo que circula nas grandes cidades.

Do rompimento com uma imagem una do mundo, os indivíduos passam a se instigar pelo divertimento, pela pluralidade e diferenciação oscilando da anestesia à hiperestesia:

É como se o homem moderno quisesse se compensar a monotonia e a uniformidade de sua atividade na divisão do trabalho, no que diz respeito à absorção e à fruição, com a crescente concentração de impressões heterogêneas e a alternância sempre mais veloz e colorida de excitações (SIMMEL [1896], 2013, p. 72).

Uma exposição da proporção da Exposição Industrial de Berlim, que reúne uma "imensidão de objetos produzida em uma cidade" (ibid., p. 73) tem como efeito para a fruição a projeção de uma ideia que paira sobre o conjunto da mostra: a Berlim daquele momento, como cidade mundial: “[...] uma cidade à qual todo o mundo entrega as matérias de seu trabalho e que transforma tais matérias no conjunto das formas essenciais que aparecem em alguma parte do mundo cultural contemporâneo" (idem.).

A forma como essa exposição e suas congêneres eram constituídas, principalmente pelo trabalho dos arquitetos que projetavam o espaço externo e interno que abrigava e exibia os objetos e obras, também parece ser fundamental para a análise de Simmel, que a toma como estilo peculiar. No estilo arquitetônico dos "pavilhões", "palácios" e "galerias" - montados de modo planejado para desmonte após o fim da mostra -, ele identifica os aspectos de transitoriedade e instabilidade como suas marcas 
inconfundiveis ${ }^{21}$. A fantasia de duração que os arquitetos buscavam criar, ainda que não mais pautada pela monumentalidade e avançando em técnicas e materiais, não conseguia eliminar o "encanto e o aroma da transitoriedade" (ibid., p.74).

Outra atividade muito específica, relacionada à forma de expor os objetos, como "o esforço banal de colocar as coisas 'sob a luz correta" (ibid., p.75), é visto como diretamente ligada à necessidade de promover a purificação do ambiente de apresentação, para separá-lo do caos de estímulos ululantes das ruas e feiras, projetando nesses objetos outros significados, inclusive atribuindo à exposição como um todo uma nova significação estética.

No caso da Exposição Industrial de Berlim, Simmel destaca a "razão prática" característica da cidade como tomando corpo em um espaço condensado, e especula o potencial da exposição de se desenvolver, como impulso estético, na direção de uma elaboração da "forma específica da exibição dos produtos do trabalho" (ibid., p.76). A efemeridade dessas montagens, expressa em sua arquitetura, formam, na concepção do autor, um estilo próprio.

Partindo dessa análise restrita ao espaço da exposição industrial, Simmel identifica analogias entre sua forma e a forma de relação dos indivíduos, que são entrelaçadas pela experiência de acúmulo de impressões, pois "o objeto individual, no interior de uma exposição, mostra as mesmas relações e modificações que são próprias ao indivíduo no interior da sociedade" (ibid., p. 75): a identificação e a diferenciação oscilam a partir das similaridades entre os objetos que se avizinham, ou os indivíduos que interagem. E essa imagem se expande tanto para as formações objetivas que se originam dessa configuração (do estilo de vida moderno), como as exposições, e para o nível da subjetividade, que busca convergências entre a totalidade do $E u$ e sua compreensão como elemento de uma totalidade maior.

\footnotetext{
21 Referindo-se às exposições de arte, Simmel ([1890] 2013, p.34) enfatiza o contraste entre o seu caráter fugidio e a tranquilidade oferecida pela permanência das obras no museu, cuja vantagem se dá pela possibilidade de contemplar as peças com mais comodidade e frequência.
} 
Ainda sobre os efeitos cognitivos da forma das grandes exposições, Simmel indica sua capacidade de hipnotizar a percepção de quem ali se entretém, pois, diante da disparidade de coisas que se vê e das impressões de cada uma isoladamente, só pode fixar-se na memória aquilo que tem de repetição, para além dos atributos de conteúdo que permitem sua variação. A diversidade de ofertas se conecta à diversão gerada pela experiência de entrar em contato com tantos estímulos em um só passeio. Essa experiência acaba culminando no efeito massivo de que "aqui é preciso se divertir" (ibid., p.71).

Essa força de diversão (nos dois sentidos, de diversidade e divertimento), cujas raízes históricas são apontadas pelo autor como se encontrando nas feiras anuais, é compreendida por ele como expressa nitidamente nas grandes exposições, como o caso da industrial de Berlim. Mesmo que situando, no início do ensaio, divertimento ou prazeres sociais como parte integrante de toda socialização, elemento agregador de grupos distintos "mesmo quando os motivos e os estímulos objetivos da associação perderam sua eficácia" (idem.), Simmel sinaliza de modo crítico o efeito massivo da atmosfera de consumo e entretenimento (com bilhetes de entrada para atrações específicas, por exemplo) que essas exposições expressam e fomentam: "a abundância e a disparidade do que é oferecido fazem com que apenas a diversão subsista como fator definitivo de unificação e caracterização de seu colorido" (idem.).

Esse tipo de exposição, ao reunir a diversa e heterogênea produção industrial em uma unidade espacial e temporalmente delimitada, se tornou um fenômeno específico da vida moderna. Sua forma promove "a superficialidade mediana como coesa" (ibid., p. 73) - a forma da cultura moderna ${ }^{22}$-, podendo produzir interações de outras interações baseadas no vínculo entre os objetos expostos em um só lugar durante um curto período.

\footnotetext{
22 A concepção de Simmel de uma sociologia formal (ou sociologia das formas de associação) é moldada por sua visão vitalista da realidade. Essa se configura como "estudo sistemático das formas estruturantes dos processos de interação" (Vandenberghe, 2005, p.82). Nessa perspectiva, as organizações e instituições são compreendidas como interações de interações, como o são as "sociedades" ou "unidades". Essas interações, para formar associações, precisam dar-se na dimensão da consciência dos indivíduos que interagem sobre a unidade que suas interações compõe: "A consciência de formar com os outros uma unidade é, aqui, a única questão" (Simmel, apud. Vandenberghe, 2005, p.87).
} 
A exposição da produção de uma única cidade, no entanto, se diferencia da junção mecânica das exposições universais coetâneas, pois aquelas se apresentam como "retrato e extrato das forças industriais do mundo da cultura" (idem.), enfatizando seus vínculos pela relação com o local em que foram produzidas e na exposição reunidas: a cultura das coisas de Berlim combinadas em uma grande narrativa que se desdobra no espaço e tempo de sua aparição mesma. O efeito massivo da diversão é visto em diálogo com a progressiva especialização conduzida pela cultura moderna, sendo a diferenciação do consumo uma busca do indivíduo moderno por compensações da "monotonia e uniformidade de sua atividade na divisão do trabalho" (ibid., p.72).

No ensaio de 1896, Simmel enfatiza, próximo a sua conclusão, o desencadeamento do processo de intensificação do que chamou "qualidadevitrine" das coisas, que pode ser estabelecido pela aparência e pela mise-enscène das mercadorias, que passam a ter sua forma e disposição manipuladas com o objetivo de torná-las mais atraentes e provocativas para os compradores. Nesse ponto, Simmel identifica uma virada de ideal estético cujas relações causais estão conectadas ao dominio da livre concorrência e da luta do consumidor, e se dirige a uma tendência a atribuir aos objetos um "estimulo para os olhos", ademais de sua utilidade.

O espaço arquitetônico projetado e os efeitos de isolamento relativo entre as peças exibidas, que pode ser construído pela disposição e pela iluminação, são destacados por Simmel como as bases para a constituição de um estilo de exposição. Particularmente na Exposição Industrial de Berlim da qual parte sua reflexão, observa um potencial inovador e positivo na negação do ideal monumental histórico da arquitetura, pois teriam alcançado a capacidade de criar um pano de fundo para a exibição das mercadorias.

A exposição, como forma de reunir e exibir que passa a operar cada vez mais no sentido de sintetização entre "a atração externa e a funcionalidade objetiva das coisas", é compreendida por Simmel como espaço de entretenimento no qual o público se move pela busca de novos estímulos ao mesmo tempo em que não é capaz de reter na memória a 
singularidade de cada um deles. A exposição promove de maneira extrema, segundo o autor, a preponderância da dimensão estética da produção e do consumo de objetos, sendo a diversão sua tônica.

\section{A exposição entre estilos e personalidades}

Alguns anos antes da Exposição Industrial de Berlim, em 1890, Simmel havia publicado um ensaio sobre as exposições de obras artísticas, no qual desenvolveu de maneira mais radical a analogia entre a forma específica desse tipo de exibição de objetos e o conflito entre a expressão da individualidade e a constituição da unidade cultural.

Esse texto, intitulado Über Kunstausstellungen (Sobre Exposições de Arte), não indica um objeto singular do qual partem suas reflexões, como no caso do ensaio sobre a exposição industrial de Berlim realizada seis anos mais tarde, e parece dirigir-se a uma visão mais geral sobre esses tipos de mostras, não as conectando necessariamente a algum conteúdo específico. Simmel menciona predominantemente exemplos de pinturas, que não se restringem a um único autor, grupo ou movimento, embora evidencie que essa diversidade se trata da produção contemporânea.

$\mathrm{Na}$ sua reflexão sobre a fruição experimentada pelos visitantes da exposição industrial, Simmel também apresenta elementos fundamentais para se compreender como essa experiência difere daquela proporcionada pela exposição de arte. $O$ autor situa esse tipo de exposição no desencadeamento da divisão do trabalho, que afeta a atividade artística no sentido de sua especialização, gerando uma proliferação de personalidades criativas que se opõe à unilateralidade de um estilo identificado com uma personalidade individual ou de um grupo. Diante desse fenômeno, ele enfatiza a ânsia por maior intensidade da produção de novos estímulos (excitações, interesses e gozos), que levem o indivíduo de estados de anestesia para a hiperestesia garantida em um curto período de tempo estrito à visita, um percurso dentro de um espaço restrito que se compõe da condensação dos exemplares mais variados da capacidade de produção artística. Simmel entende o papel das exposições para seu tempo presente, visto como período instável de transição, da seguinte maneira: 
A exposição de arte é acusada de ser causa da superficialidade e arrogância do julgamento artístico, mas é, ao contrário, o efeito de certas condições do espírito público que podem ser lamentadas, mas que estão tão entrelaçadas que seria impossivel retirá-las sem mudar todo o tom da sensibilidade da vida moderna. Poucas outras manifestações, que, como a exposição de arte, são frutos um pouco periféricos da nossa cultura, apresentam tantos aspectos diferentes de seu caráter em forma tão comprimida: a especialização do trabalho, a concentração das mais diversas forças em um só espaço limitadíssimo, a pressa ofegante e a excitante caça por impressões (SIMMEL [1890], 2016, p. 166, grifos meus).

Após a introdução do ensaio, em que relaciona a exaltação estética do passado ao pessimismo sobre os fenômenos que se oferecem no presente, Simmel busca identificar na forma das exposições de arte o meio através do qual se projeta alguma noção de unidade, ou estilo, tanto para a produção moderna de obras artísticas quanto para a sensibilidade moderna. Essas não mais têm capacidade de se apoiar em personalidades expressas de modos bem definidos através de séries de obras, como quando a 'genialidade' de criadores individuais como seria o caso dos grandes mestres da pintura Renascentista, especialmente Michelangelo e Botticelli, ou de outros contextos do passado, como Velásquez, Rembrandt, Goya, ou ainda como representantes da música e da literatura, respectivamente, Beethoven e Goethe, é substituída pela estilização (regularidade apresentada entre partes de um coletivo), negando a essência e o valor individuais da obra de $\operatorname{arte}^{23}$. Simmel caracteriza a nova visão do espírito público sobre a história de maneira geral e a arte particularmente como pautada pela eficiência da massa, cooperação de muitos e conquistas coletivas: "A originalidade foi transferida do indivíduo para o grupo, ao qual ele pertence e do qual ele empresta seu modo de criação" (ibid., p. 165).

A exposição de arte é compreendida por Simmel como "o complemento e a consequência necessária da especialização moderna da arte” (ibid., p. 160), manifestação e emblema de uma série de transformações pelas quais vem passando. Seu desenvolvimento, cada vez mais especializado, como já referido, também passa a se distribuir demograficamente, com o aumento do número de produtores que se concentram nas grandes cidades. A partir disso o autor propõe a imagem de uma constelação de pequenas estrelas que

23 Ver: SIMMEL, G. [1908] 2016. 
vagueiam como a representação possível dessa dinâmica, da qual emerge a necessidade de reunir todas as "habilidades" diversas num só lugar e momento em que se possa "conhecer a arte da atualidade" (idem.) e "experimentar as mais variadas sensações" (ibid., p. 161), que essa arte possa suscitar.

A exposição como forma de reunião da diversidade que oscila entre as pequenas variações de personalidade no interior de estilos que coexistem cada vez em maior pluralidade, tanto das obras de arte quanto dos objetos da indústria, principalmente com as artes aplicadas e o design sendo integrados a ela, é vista como uma miniatura dessa constelação, que abarca as correntes espirituais mais diversas de seu presente.

A imagem geral que se projeta nas exposições de arte, como no caso da exposição industrial, é transmitida por uma abundância de direções, ideias e práticas, sendo o papel da exposição, como reitera Simmel, o de sintetizar essa diversidade e apresentá-la ao refinamento das sensibilidades do público moderno. Essa instituição, embora fruto secundário, passa a ser indispensável como "indicador simbólico" para o espírito moderno.

A falta dos gênios definidos como manifestação de uma individualidade, à análise de Simmel, parece tender a ser suprida "grande riqueza de buscas, tarefas e tipos de estilo assumidos pelo grupo inteiro" (ibid., p. 166). Diante do rompimento com a imagem canônica da produção artística, com uma arte una, o diagnóstico que elabora sobre seu presente aponta para a perda da faculdade de julgar, devido à superficialidade e à arrogância, "maiores males da sensibilidade artística moderna" (ibid., p. 162).

A imensidão dessa diversidade difusa, caracterizada por Simmel, parece objetivamente inalcançável em sua variedade. Para a consciência do público resta captar aquela imagem geral, residual, calcada nos elementos que se repetem e criam uma imagem memorável, da mistura de impressões ${ }^{24}$, que sempre se percebe como instável, ainda mais quando se busca cada vez mais por novos estímulos, sem que se dirija a uma

\footnotetext{
24 Em seu ensaio A moldura Simmel aborda mais profundamente essa ideia de isolamento relativo
} entre as obras expostas. Ver: Simmel [1902], 2016. 
compreensão profunda de alguma obra em sua individualidade (já que esta será sempre afetada pelas que se avizinham e se justapõem na memória de quem as contempla).

Simmel fala de uma consciência e um imaginário "superlotados", saturados e exacerbados por tantos estímulos. Essa condição dificulta ou impede a conexão do indivíduo com a unidade de cada objeto e obra expostos no sentido de uma entrega "idílica" ao interior de seus limites. Ao mesmo tempo, a coexistência de diversos estímulos num mesmo espaço contribui para a dispersão da atenção, e leva o indivíduo a extrair, da variedade de estilos apresentados, uma totalidade que apazigue sua consciência. Após dispor seu corpo e sua mente a contemplar e confrontar tantos impulsos, a agitação da percepção do indivíduo retorna ao estado de anestesia. Os estímulos presentes nas exposições se objetivam na fruição hiperestésica da grande diversidade de objetos reunidos num mesmo espaço e vistos ao longo de uma caminhada. Essa experiência delimitada ao tempo de visita da exposição se encontra de maneira análoga e em escala ampliada na vivência dos indivíduos nos espaços urbanos em rápido crescimento e adensamento na virada do século XIX para o XX. Essa analogia proposta por Simmel compreende a configuração das exposições como uma forma comprimida da dinâmica das metrópoles e o tipo de percepção que a vida em seu interior modela.

\section{As exposições e o estilo de vida do espectador moderno}

“Quem é o espectador?” - retomo a questão do crítico O’Doherty inserida alguns parágrafos acima e tento repensá-la a partir das ideias de Simmel apresentadas neste artigo. Em ambos textos que busquei enfocar, as exposições são tomadas como símbolo da modernidade, pois encerram em si sintomas de sua dinâmica e temporalidade, como efeitos da necessidade de gerar uma totalidade dentro da qual se contemple a diversidade de realizações possiveis no interior da sociedade moderna. A circulação de pessoas e objetos ao longo desses eventos se concretizam a cada instante na forma de incessantes impressões sobre a diversidade de estilos artísticos, arquitetônicos, de decoração e vestuário. Os corpos que afluem no interior 
dos limites físicos dessas mostras acumulam estímulos e percepções externos a ela, das ruas, vitrinas, jornais, publicidade e das interações entre pessoas na multidão.

A operação cognitiva a que se refere Simmel ao considerar a retenção de uma imagem geral na memória a partir da sucessão de imagens expostas no mesmo evento, pode ser vista de maneira ainda mais complexa e fluida quando tomamos a dimensão estética da experiência de viver nas grandes cidades. Pois para além das imagens das obras, a mente do espectador evoca outras justaposições de estímulos visuais que se dão ao longo de seu deslocamento, antes de entrar na exposição e depois de sair dela.

Da maneira como Simmel concebe a significação do dinheiro na determinação do compasso da vida, como onipresente, base para uma infinidade de interações, parece que os estímulos, como base da dimensão estética da vida na metrópole, também são possiviveis de ser compreendidos com um papel de magnitude análoga. Seja pela atitude de indiferença (quando o estímulo não suscita reação ativa do indivíduo), seja pela busca progressiva de novidades (quando os estímulos existentes já não são suficientes para se divertir), o indivíduo na grande cidade desloca-se a experimentar sensorialmente seus espaços, imagens, movimentos, ruídos, odores...

Os dois tipos de exposição abordados por ele, e pela maneira como o faz, observados como uma espécie de evento singular, uma unidade composta pela diversidade da produção industrial ou artística disposta em um reduto específico em tempo e espaço, integram o estilo de vida moderno. As grandes exposições em sua forma são elementos centrais da cultura que emerge da configuração das metrópoles, ainda que o autor as identifique como efeitos secundários de sua dinâmica. Ao mesmo tempo, parecem encerrar em seu interior (e talvez isso possa ser dito, com bastante cuidado, em relação a muitos de seus objetos expostos), como relações análogas àquelas que Simmel identifica na própria sociedade moderna como uma totalidade mais ampla.

As exposições parecem figurar como uma miniatura da sociedade dentro dela mesma. A despeito da especificidade dos objetos a que se 
dedicam, sejam obras de arte ou artefatos da indústria, as relações entre os objetos apresentados reunidos num mesmo ambiente, integram uma imagem reduzida das relações mais amplas que se operam nessa sociedade: as exposições podem ser compreendidas como a forma que aglutina (atualizando-se temporariamente) os desenvolvimentos das tecnologias e estilos possibilitados pela divisão social do trabalho, o adensamento populacional nos espaços urbanos e da rede de interações entre indivíduos, que leva à mediação cada vez mais necessária do dinheiro, parece também ser a que torna as exposições dispositivos necessários para o contato com a produção que resulta de seu funcionamento.

O espectador da exposição seria uma miniatura do indivíduo que transita nas grandes cidades, entre a atitude blasé que ignora determinados estímulos e atitude compulsiva por novidades estilisticas para seu consumo? O olhar do espectador de Simmel não se descola de um fluxo de percepções de estímulos que afetam o corpo de cada indivíduo na multidão que transita as grandes cidades, entre a anestesia e hiperestesia. As exposições que se consolidam no fim do século XIX e ganham um caráter de agenda ininterrupta para o estímulo ao longo do século $\mathrm{XX}$, parecem constituir o elemento que sincroniza o espectador à temporalidade do estilo de vida moderno, que não pode acompanhar a fadiga do museu (como no caso estudado por Gilman), como instituição de exposição permanente, imutável, que não se afeta pela novidade.

\section{Considerações finais - ou sobre olhar as exposições em outros tempo:}

Os dois ensaios de Georg Simmel sobre as exposições analisados neste artigo, como sugere o sociólogo Arthur Bueno (2013), podem ser situados como parte de um conjunto de textos publicados na década de 1890 nos quais o autor analisa fenômenos específicos da sociabilidade no contexto das grandes cidades de sua época, atentando-se especialmente a suas dimensões sociológica e psicológica. Os temas relacionados à experiência estética e ao entretenimento da maneira como abordados por Simmel provocam um movimento de reflexão que se instala nos processos de afetação mútua entre o caráter psicológico dos indivíduos e as condições 
gerais que configuram o moderno estilo de vida. Sua perspectiva situa a percepção (os nervos) de quem transita pelas ruas das metrópoles ou pelas galerias e pavilhões de exposições numa dinâmica circular de causa e efeito entre anestesia e hiperestesia - oscilação entre estados extremos de reação a estímulos sensoriais que Simmel "em sintonia com a psicologia de sua época chamou neurastenia" (BUENO, 2013, p.159).

Esse aspecto da vida mental compõe o eixo através do qual Simmel dirige sua compreensão da modernidade em paradoxos, contemplando as tensões entre opostos que se intensificam à medida que a diferenciação interna das atividades humanas segue seu ritmo progressivo de expansão. A crítica que o autor exprime em sua análise de fenômenos como as exposições reside na noção de que a adaptação psíquica dos indivíduos ao ambiente de intensa e extrema oscilação nervosa - a renúncia a reagir figurada no blasé, leva à busca permanente de satisfações que se cumprem de modo contingente e superficial. No entendimento de Simmel, esses aspectos da experiência moderna se desenvolvem na relação com o tempo e o espaço, e tomam as possibilidades de formação cultural e individual (Bildung). Esse sentido de desdobramento das consequências do moderno estilo de vida é encarado por Simmel como trágico, conflituoso, contraditório.

O pesquisador Leopoldo Waizbort (2000) também oferece uma leitura em diálogo desses dois ensaios de Simmel sobre as exposições, centrando sua análise sobre as considerações acerca das noções de "variedade e multiplicidade" que caracterizam a concepção do filósofo-sociólogo sobre o moderno estilo de vida. As exposições para Simmel, embora reconhecidamente “desagradáveis e pouco úteis" (SIMMEL, [1890] 2016, p.166), tornaram-se indispensáveis para sua compreensão do moderno, como causas e consequências de aspectos de sua configuração. Waizbort aponta para a curiosa ausência de menções às exposições entre os inúmeros exemplos apresentados por Simmel em seu Philosophie des Geldes, publicado vinte anos mais tarde, no qual o dinheiro é entendido como o elemento que simboliza a modernidade.

O pesquisador indica ainda a pertinência que persiste na maneira como Simmel situa as exposições no processo de diferenciação e divisão do 
trabalho, pois essas seriam formações "convenientes" (WAIZBORT, 2000) à necessidade de encontrar os resultados da diferenciação convivendo lado a lado e ao alcance da vista de maneira breve. Waizbort chama atenção ainda para a circulação do próprio Simmel num grande magazine berlinense, algo que se assemelha aos atuais shopping-centers enormes, repletos de vitrines e pessoas, com "a mais ampla diferenciação dos objetos ao seu dispor" (ibid., p.351), onde se busca usufruir da multiplicidade de produtos e satisfazer sua necessidade por novos e diversificados estímulos.

Essa condição vivida pelos indivíduos nas grandes cidades dos tempos de Simmel pode ser compreendida como um estágio de consolidação do processo progressivo de adensamento e diferenciação que nas últimas décadas do século XX se apresenta de forma radicalizada, como sugere, por exemplo, o sociólogo Anthony Giddens (1991). Pensando a exposição como uma forma de associação que perdura até os dias atuais, é possível buscar na contribuição de Simmel alguns caminhos de análise do significado dela para a contemporaneidade. A analogia entre as exposições e as grandes cidades ou a modernidade conforme apresentada por Simmel, pela amplitude de relações que sua observação busca captar e continua oferecendo instigante parâmetro para análise das exposições na contemporaneidade.

Análises mais recentes resultantes de pesquisas em sociologia da arte, por exemplo, indicam que as transformações observadas no âmbito da produção, circulação e recepção de obras artísticas tem forte influência da penetração da lógica de operação das exposições na organização das atividades dos museus (MOULIN, 2007). Nesses, se insere a intensificação do investimento em exposições temporárias de curadorias que partem de seus acervos ou da exibição de mostras itinerantes de diferentes coleções. Também se observa a articulação entre mídia, mercado e entretenimento para atrair o público às novas (ou renovadas) instituições culturais (MOULIN, 1992), como as bienais, quadrienais e feiras. As análises de Simmel sobre as exposições de seu tempo parecem ainda prover uma perspectiva potente para os estudos históricos, sociológicos, antropológicos, psicológicos e estéticos das exposições da produção artística e tecnológica na 
atualidade. Os dois ensaios de Simmel conseguem provocar o olhar sobre as exposições em sua relação com outros espaços e formas de sociabilidade "comprimindo" os conteúdos das peças exibidas em conexão com as cadeias mais amplas de produção de objetos e com a dimensão estética mais abrangente da vivência nas metrópoles saturadas de estímulos. Também oferece caminhos para se pensar as condições psíquicas de recepção estética dos indivíduos, as afetações mútuas entre a arquitetura e a expografia das mostras e os aspectos que envolvem uma "compressão" entre tempo, espaço e as configurações dos sentidos na dinâmica de vida que flui nos contextos em que as exposições se formam.

\section{Referências bibliográficas}

BAUDELAIRE, Charles. Exposition Universelle 1855. In: BAUDELAIRE, Charles. II Curiosités Esthétiques - Oeuvres Complètes. Paris: Michel Lévy Frères Libraires Éditeurs, 1868.

BUENO, Arthur. Posfácio: Simmel e os paradoxos da cultura moderna. In: BUENO, Arthur (org.). O Conflito da Cultura Moderna e outros escritos. Tradução: Laura Rivas Gagliardi. São Paulo: Editora Senac São Paulo, 2013.

BYDLER, Charlotte. The Global Art World Inc. On the Globalization of Contemporary Art. Uppsala: Uppsala University Press, 2004.

FRISBY, David. [1990] Afterword: The Constitution of the Text. In: SIMMEL, Georg. The Philosophy of Money. FRISBY, D. (ed.). Tradução: Tom Bottomore e David Frisby. 3a ed., Londres/Nova York: 2004.

GIDDENS, Anthony. As consequências da modernidade. Tradução: Raul Fiker. São Paulo: Editora Unesp, 1991.

GILMAN, Benjamin Ives. Museum Ideals of Purpose and Method. Cambridge-MA: Boston Museum of Fine Arts/Riverside Press, 1918.

MOULIN, Raymonde. L'artiste, l'institution et le marché". Paris: Flammarion, 1992.

O mercado de arte: mundialização e novas tecnologias. Tradução: Daniela Kern. Porto Alegre: Zouk editora, 2007.

O’DOHERTY, Brian. No interior do Cubo Branco: A ideologia do espaço da arte. Tradução: Carlos Mendes Rocha. São Paulo: Martins Fontes, 2002.

PESAVENTO, Sandra Jatahy. Exposições Universais: Espetáculos da Modernidade do século XIX. São Paulo: Editora Hucitec, 1997. 
SIMMEL, Georg. [1890] Sobre exposições de arte. In: VILLAS BÔAS, Glaucia; OELZE, Berthold (org.). Georg Simmel arte e vida: ensaios de estética sociológica. Tradução: Markus André Hediger. São Paulo: Hucitec, 2016.

SIMMEL, Georg. [1890] Sobre as exposições de arte. In: BUENO, Arthur (org.). O Conflito da Cultura Moderna e outros escritos. Tradução: Laura Rivas Gagliardi. São Paulo: Editora Senac São Paulo, 2013.

. [1896] Exposição Industrial de Berlim. In: BUENO, Arthur (org.). o Conflito da Cultura Moderna e outros escritos. Tradução: Laura Rivas Gagliardi. São Paulo: Editora Senac São Paulo, 2013.

. The Philosophy of Money. FRISBY, D. (ed.). Tradução: Tom Bottomore e David Frisby. $3^{a}$ ed., Londres/Nova York: 2004.

. Tendencies in German life and thought since 1870. In: International Monthly, Nova York: n.5, 1902.

[1917] Sobre a caricatura. In: VILLAS BÔAS, Glaucia; OELZE, Berthold (org.). Georg Simmel arte e vida: ensaios de estética sociológica. Tradução: Markus André Hediger. São Paulo: Hucitec, 2016.

[1903] As grandes cidades e a vida do espírito. In: MANA, Rio de Janeiro, v.11, n.2, outubro, 2005. Tradução: Leopoldo Waizbort.

[1908] O Problema do Estilo. In: VILLAS BÔAS, Glaucia; OELZE, Berthold (org.). Georg Simmel arte e vida: ensaios de estética sociológica. Tradução: Markus André Hediger. São Paulo: Hucitec, 2016.

[1908] Essai sur la sociologie des sens. In : SIMMEL, G. Sociologie et Épistémologie. Paris: Presses Universitaires de France, 1981.

[1918] O conflito da cultura moderna. In: BUENO, Arthur (org.). Georg Simmel - O Conflito da Cultura Moderna e outros escritos. Tradução: Laura Rivas Gagliardi. São Paulo: Editora Senac São Paulo, 2013.

[1911] A moda. In: IARA - Revista de Moda, Cultura e Arte v.1 n.1, abril/agosto, 2008, São Paulo. Tradução: Antônio Carlos Santos.

[1917] A crise da cultura. In: BUENO, Arthur (org.). O Conflito da Cultura Moderna e outros escritos. Tradução: Laura Rivas Gagliardi. São Paulo: Editora Senac São Paulo, 2013.

[1918] A forma da histórica. In: SIMMEL, Georg. Ensaios sobre teoria da história. Tradução: Estela dos Santos Abreu. Rio de Janeiro: Contraponto, 2011.

[1902] A moldura. In: VILLAS BÔAS, Glaucia; OELZE, Berthold (org.). Georg Simmel arte e vida: ensaios de estética sociológica. Tradução: Markus André Hediger. São Paulo: Hucitec, 2016. 
Arte e cidade comprimidas | Tálisson Melo de Souza

VANDENBERGH, Frédéric. As sociologias de Georg Simmel. Tradução: Marcos Roberto Flamínio Peres. Bauru - SP / Belém - PA: EDUSC / EDUFPA, 2005.

WAIZBORT, Leopoldo. As Aventuras de Georg Simmel. São Paulo: Editora 34, 2000. 